\title{
Pelabelan Produk dan Merek Dagang untuk Promosi Penjualan pada Warung Armina Karang Pule
}

\author{
Phyta Rahima ${ }^{1}$, Suriyati ${ }^{2}$, Hilda Hastuti ${ }^{3}$ \\ Phytarahima@universitasbumigora.ac.id ${ }^{1}$, Suriyati@universitasbumigora.ac.id ${ }^{2}$, \\ Hildahastuti@universitasbumigora.ac.id \\ 1,2,3Universitas Bumigora
}

Article History:
Received: $11-11-2021$

Revised: 18-01-2021

Accepted: 26-01-2021

Keywords: Warung

Armina, Brand and Labels

\begin{abstract}
The development of home-based businesses in Indonesia is very rapid, especially in areas such as the island of Lombok. Most people depend on their economy from selling, starting from selling clothes, children's toys and household furniture, but in Mataram city itself is already busy with home-based food businesses whose activists are housewives who want to increase their income. pocket money or monthly money and looking for a job. The business that is currently booming is the geprek chicken business which is easily found along the streets of Mataram City. Geprek chicken business itself is a business that is classified as very easy to do because its composition only consists of chicken coated with crispy flour, added with rice and cucumber vegetables and chili sauce, with a price of 10,000, - including iced tea. Meanwhile, the partner in this service is Warung Armina. Warung Armina is located in the Karang Pule neighborhood of Mataram City. In the development of its business, Warung Armina is only run by a couple who rely on neighbors and motorcyclists who pass in front of the house so that it becomes an attraction for our team to provide service to Armina's stall until we get the right model for labeling and packaging. These activities are carried out by observing, interviewing and having direct dialogue with shop owners about the desires and obstacles they face. With a comfortable dialogue, the expected end result is the right label and promotion for lapak armina to registration of lapak Armina at online platform.
\end{abstract}

\section{Pendahuluan}

Banyaknya masyarakat yang saat ini membuka lapangan usaha khususnya rumah makan seperti warung dan rumah makan siap saji menyebabkan meningkatnya jumlah persaingan yang ada terlebih lagi ketika di hadapkan dengan situasi yang sebagian besar masyarakat pekerja saat ini dirumahkan karena terdampak Pandemi sehingga para pemilik usaha harus memutar otak agar bisa memutar uang atau modal mereka dengan tujuan agar asap dapur tetap mengepul dan untuk memenuhi kebutuhan sehari-hari. Warung Armina adalah salah satu Usaha rumahan yang belum menerapkan strategi promosi dengan label dan merek dagang yang diharapkan hanya masih mengandalkan orang-orang sekitar dengan banner seadanya.

Dengan adanya hal tersebut diatas maka kami selaku tim Pengabdi mencoba memberikan focus kegiatan pengabdian ini dari segi strategi promosi dengan mengutamakan merek dan label usaha sehingga diharapkan nantinya kegiatan ini mampu 
membantu Warung Armina untuk lebih mengembangkan lagi sayap usaha mereka karena bias dikatakan bahwa Warung Armina menjual makanan dengnan harga yang cukup terjangkau apalagi dikalangan anak muda dan ditengah Pandemi saat ini. Alasan pendampingan pada warung armina adalah karena warung armina adalah warung makan yang posisinya sangat jauh dari jalan raya dan dengan owner yang mencoba menjual hanya melalui rumah saja tidak membuka outlet atau gerai di tempat yang ramai sehingga kami selaku tim pengabdi mencoba memberikan saran dengan memperluas pasar salah satunya adalah dengan melakukan branding dan promosi melalui pelabelan dan promosi dengan cara memperluas merk. Menurut (Hintermann Geneva, n.d.)Fungsi utama dari sebuah merek adalah agar konsumen dapat mencirikan suatu produk (baik itu barang maupun jasa) yang dimiliki oleh perusahaan sehingga dapat dibedakan dari produk perusahaan lain yang serupa atau yang mirip yang dimiliki oleh pesaingnya. Konsumen yang merasa puas dengan suatu produk tertentu akan membeli atau memakai kembali produk tersebut di masa yang akan datang. Untuk dapat melakukan hal tersebut pemakai harus mampu membedakan dengan mudah antaraproduki yang asli dengan produkproduk yang identik atau yang mirip.

Menurut (Kotler, 2014) pengertian branding adalah pemberian nama, istilah, tanda, simbol, rancangan, atau kombinasi dari kesemuanya, yang dibuat dengan tujuan untuk mengidentifikasikan barang atau jasa atau kelompok penjual dan untuk membedakan dari barang atau jasa pesaing. Sementara menurut (Ainurrofiqin, 2021) pengertian branding adalah bukanlah sekedar merek atau nama dagang dari sebuah produk, jasa atau perusahaan. Namun semuanya yang berkaitan dengan hal-hal yang kasa mata dari sebuah merek; mulai dari nama dagang, logo, ciri visual, citra, kredibilitas, karakter, kesan, persepsi, dan anggapan yang ada di benak konsumen perusahaan tersebut.

Pengabdian Masyarakat yang dilakukan oleh (Yuliani \& Widyakanti, 2020) memiliki tujuan untuk untuk meningkatkan penjualan pada UMKM sehingga produk ini dapat dijual di pasar modern. Permasalahan mitra dalam kegiatan ini adalah proses produksi masih menggunakan alat-alat yang sangat tradisional, kemasan produk yang sangat sederhana, label yang kurang menarik dan belum adanya $P$-irt sehingga produk ini hanya sampai pada pasar tradisional. Hasil dari kegiatan ini adalah proses produksi yang lebih cepat dengan menggunakan mesin pemotong keripik tempe, kemasan menggunakan standing pouch, desain label menarik, adanya sertfikat keamanan pangan yang diterbitkam dinas kesehatan Pemerintah kota Banjarmasin maka pangsa pasar UMKM meningkat pada pasar modern.

Adapun solusi yang ditawarkan dalam kegiatan pengabdian ini adalah memberikan ide dan solusi untuk membuat desain merek, banner dan daftar menu pada warung Armina tentunya dibantu oleh Tim Design yang berpengalaman sehingga tampilan https://journal.universitasbumigora.ac.id/index.php/ADMA 
promosi menjadi lebih menarik dan kegiatan promosi bisa terlaksana dengan baik. Dengan adanya Kegiatan ini Mitra akan dibantu dan difasilitasi untuk kegiatan Promosi mereka, mulai dari Pencetakan stiker, Penempelan Banner dan promosi melalui media social karena memang jantungnya usaha rumahan adalah promosi melalui media social dibantu lagi oleh penempatan penjualan melalui platform Grabfood dan Gofood

Dalam penentuan merek, stiker dan startegi periklanan hal yang juga harus diperhatikan struktur iklan seperti warna, gambar dan nilai estetika yang bias diterima masyarakat. Dalam artikel yang ditulis oleh (Yoga Pratama \& Purwaningsih, 2021) dijelaskan bahwa Struktur iklan dapat diklasifikasikan menjadi lima, yaitu headline, illustrations, body copy, signature line, standing details (Leech, 1966). Headlinemerupakan pembuka sebuah iklan, ilustration sebagai pemberi ilustrasi iklan tersebut, body copy merupakan isi sebuah iklan yang berisi informasi dan pesan iklan, signature linesebagai tampilan produk yang diiklankan, standing detailsmerujuk pada penutup iklan. Selain itu, hal yang terpenting lainnya merujuk pada strategi pemasaran produk melalui iklan. Strategi pemasaran produk melalui iklan meliputi establishing credentials, introducing the offer, offering incentive, enclosing documents, soliciting respons, using pressure tactics, serta ending politely. Beragam informasi pada iklan produk makanan dapat memengaruhi masyarakat dalam hal keputusan pembelian produk makanan tersebut. Pengaruh yang terjadi terdiri dari attitude towards the ads (Kotler. \& Keller, 2009), ads recall, dan klik throught rates.

\section{Metode}

Penelitian yang dilakukan oleh (Puspitasari \& Gusfa, n.d.) Metode Pelaksanaan yang dilakukan adalah Pendampingan dimana mitra diajak bersama-sama untuk mencari solusi terbaik guna melakukan startegi promosi penjualan makanan pada Warung Armina. Penelitian kualitatif ini mencoba untuk mendeskripsikan Strategi promosi media sosial instagram, saat ini banyak dimanfaatkan oleh perusahaan, organisasi, maupun perorangan untuk membuat online shop. Mereka menggunakan media sosial untuk berkomunikasi dalam mempromosikan produk dan interaksi antara perusahaan dengan konsumennya. Konsumen di media sosial lebih interkatif, mereka dapat diajak untuk melakukan sesuatu dan dapat menerima informasi dari siapapun. Perusahaan yang menggunakan media sosial perlu melakukan kolaborasi dengan konsumen dalam mempromosikan produk mereka sehingga dapat terjadi keterikatan antara keduanya. Melalui media dan co-creation konten merupakan inovasi dalam menciptakan produk dan pengalaman kolaborasi antara konsumen dengan perusahaan sehingga saling terhubung (Beyond Promotion) dan membangun brand engagement. Berdasarkan hasil penelitian, strategi promosi online shop yang dilakukan Hijab Sally Heart dengan menggunakan 
konten gambar dan video mengusung tema muslimah dan konsep persahabatan untuk menciptakan komunikasi dengan konsumennya melalui media sosial Instagram sebagai media yang digunakan. Dengan adanya implementasi konten yang dibuat, menghasilkan keterlibatan emosional secara spiritual antara online shop dan konsumen

Penelitian lainnya dilakukan oleh (Hayati, Amelia, \& Putri, 2020) Mitra dalam pengabdian ini adalah pengrajin kaos di Desa Mejing Wetan, Kecamatan Gamping, Kabupaten Sleman, D.I Yogyakarta. Mitra berkontribusi memberi penjelasan terkait kondisi dan masalah yang dihadapi oleh Mitra, yang selanjutnya Tim Pengabdi akan memberikan solusi yang tepat. Permasalahan yang ditemukan pada Mitra adalah pengemasan produk kaos masih sederhana dan kurang menarik. Masalah kedua, inovasi desain kaos masih kurang dan belum memasukkan kearifan budaya lokal dan unsur religius. Solusi yang ditawarkan kepada Mitra adalah pelatihan dan pendampingan pengemasan produk kaos. Solusi kedua adalah pelatihan dan pengembangan desain kaos berbasis kearifan budaya lokal dan menambahkan unsur religius. Berdasarkan hasil musyawarah, pihak Mitra berkontribusi menyediakan tempat dan waktu selama kegiatan pendampingan, pelatihan, dan monitoring usaha berlangsung. Program PKM ini memberikan beberapa kontribusi nyata dan dapat dirasakan oleh Mitra, yaitu: meningkatkan kualitas dan inovasi produk (kaos) agar memiliki daya jual yang lebih tinggi dan meningkatkan pendapatan Mitra. Hasil akhir kegiatan PKM ini menghasilkan inovasi produk yaitu berupa kaos dengan desain kearifan budaya lokal dengan memasukkan unsur religius serta inovasi kemasan (packaging) yang terbuat dari kardus berbentuk balok dengan desain kekinian.

Warung Armina adalah Usaha rumahan yang dikelola oleh Bapak Haji Mawardi dan Ibu Hajjah Harmiati, Usaha rumahan ini menjual beberapa menu diantaranya yang paling diminati dengan harga paling terjangkau adalah Ayam geprek 10.000, Nasi Padang, Nasi Goreng dan Nasi Kebuli.

Dalam menjalankan usahanya Warung armina belum menerapkan bauran pemasaran sepenuhnya. Menurut Kotler Amstrong (2009) dalam (Pratama, Supatminingsih, Dinar, JI Raya Pendidikan, \& UNM Gunung Sari Baru Makassar, n.d.) Marketing mix atau bauran pemasaran adalah seperangkat alat pemasaran taktis-produk, harga, promosi, dan distribusi yang untuk menghasilkan respon pasar yang diinginkan pasar sasaran". Bauran

pemasaran tersebut menggambarkan pandangan penjual tentang alat pemasaran yang digunakan untuk memberi pengaruh kepada pembeli.

Dalam kegiatan Usahanya Warung Armina hanya dijalankan oleh 2 orang saja yaitu Suami istri tanpa adanya karyawan sehingga focus kegiatan yang dilakukan hanya memasak dan menanti konsumen datang tanpa melakukan penjualan melalui aplikasi 
ADMA

Dennal Pengabdian dan Pemberdayaan Masyarakat
2022, Vol.2, No.2, pp.293-304

Doi: $10.30812 /$ adma.v2i2.1557

Dalam kegiatan pengabdian yang dilakukan ada beberapa orang yang terlibat diantaranya; Ketua Pengabdi, Anggota Pengabdi, Tim Desain, Pemiliki Warung Armina yang bersangkutan.

Metode yang kami gunakan adalah Wawancara dan Observasi kira-kira daya Tarik apa yang dapat dikembangkan pada warung armina sehingga konsumen tidak hanya mengandalkan konsumen local saja, adapun kegiatan yang dilakukan adalah :

Tabel 1. Kegiatan pelaksanaan pengabdian

\begin{tabular}{|c|c|c|c|}
\hline No & Kegiatan Pelaksanaan & Penanggung Jawab & Keterangan \\
\hline 1 & $\begin{array}{l}\text { Pengenalan tentang } \\
\text { Promosi Penjualan, } \\
\text { Strategi yang seharusnya } \\
\text { dilakukan dan menentukan } \\
\text { siapa saja yang menjadi } \\
\text { konsumen }\end{array}$ & $\begin{array}{l}\text { Ketua Pengabdian dan } \\
\text { Anggota }\end{array}$ & $\begin{array}{llr}\text { Dilakukan } & \text { dengan } & \text { Metode } \\
\text { Wawancara dan diskusi serta } \\
\text { bertukar pikiran } \\
\text { memperolah hasil yang diharapkan }\end{array}$ \\
\hline 2 & $\begin{array}{l}\text { Penentuan Desain untuk } \\
\text { Banner logo dan Stiker } \\
\text { Kemasan }\end{array}$ & $\begin{array}{l}\text { Tim Design Dan } \\
\text { Pelaksana Kegiatan } \\
\text { Pengabdian }\end{array}$ & $\begin{array}{l}\text { Penyatuan Persepsi Untuk Design } \\
\text { dan Warna Banner serta Stiker yang } \\
\text { pas untuk Warung Armina }\end{array}$ \\
\hline 3 & $\begin{array}{l}\text { Dokumentasi Warung } \\
\text { Armina }\end{array}$ & Pelaksana Pengabdian & $\begin{array}{l}\text { Pengambilan Gambar Tampak } \\
\text { Depan Warung, Produk Makanan } \\
\text { yang dijual }\end{array}$ \\
\hline 4 & $\begin{array}{l}\text { Pencetakan Banner dan } \\
\text { Print stiker Kemasan } \\
\text { Warung Armina }\end{array}$ & $\begin{array}{l}\text { Tim Desain dan Tim } \\
\text { Pengabdi }\end{array}$ & $\begin{array}{l}\text { Proses Pemilihan Kemasan yang } \\
\text { cocok digunakan sesuai dengan } \\
\text { stiker yang dicetak }\end{array}$ \\
\hline
\end{tabular}

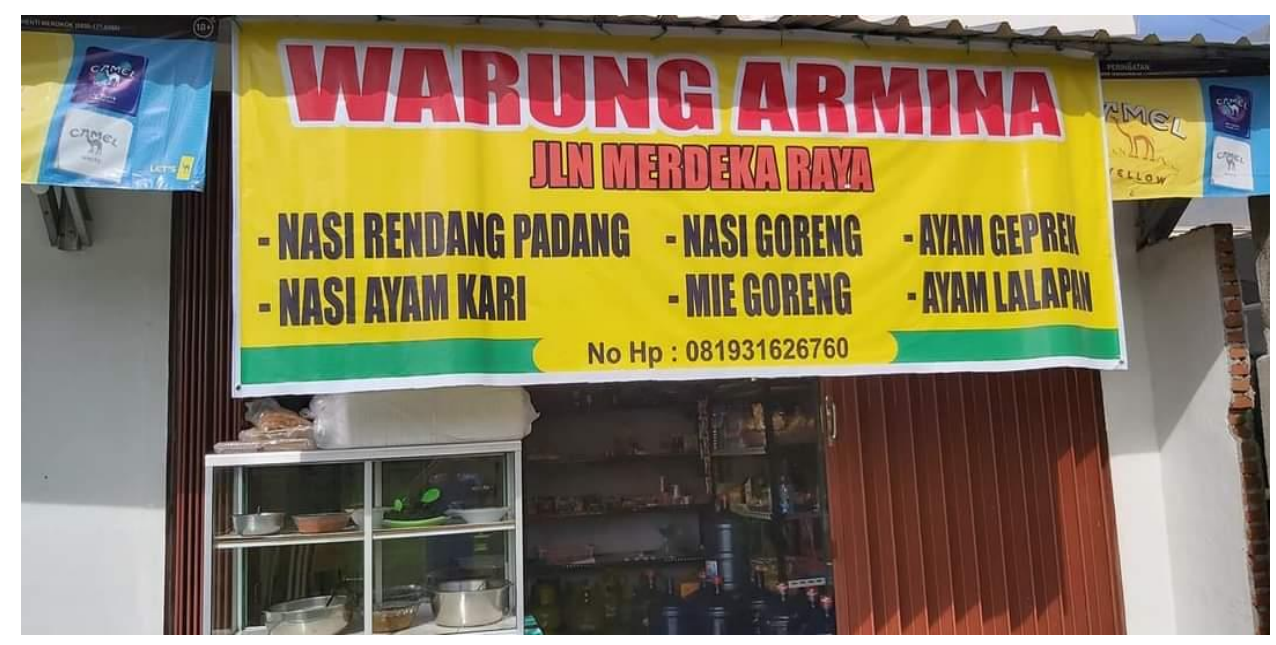

Gambar 1 Tampak Depan Warung Armina sebelum Kegiatan Pengabdian 


\section{Pembahasan}

Kegiatan utama yang dibahas dalam Pengabdian ini adalah cara yang sebaiknya dilakukan oleh Warung Armina untuk meningkatkan Strategi penjualan melalui media promosi baik itu berupa inovasi kemasan, banner stiker dan Pamflet yang menjanjikan gambar dengan pilihan yang beragam sehingga Produk dari Warung Armina tidak hanya dinikmati oleh masyarakat sekitar akan tetapi diharapkan masuk ke pasar yang lebih modern dengan cita rasa local seperti hotel-hotel kantor maupun kegiatan-kegiatan formal lainnya.

Warung Armina diharapkan akan mengembangkan usaha melalui strategi Pemasaran. Menurut Artikel yang ditulis oleh (Pratama et al., n.d.) Startegi Pemasaran adalah Strategi pemasaran adalah salah satu langkah awal yang dilakukan perusahaan dalam pengenalan produk pada konsumen dan hal ini sangat penting karena berhubungan dengan keuntungankeuntungan yang akan didapatkan oleh perusahaan

Produk Makanan yang dijual oleh Warung Armina diharapkan mampu menembus kota Mataram karena jika dilihat dari harga yang relative lebih murah dan dengan rasa yang enak maka Produk Warung Armina layak dijadikan referensi makanan terjangkau dan enak saat ini oleh karena itu diperlukan label dan merek dagang yang membuat produuk makanan yang dijual oleh warung armina memiliki label atau kemasan yang lebih baik karena tidak kalah dengan makanan makanan franchise yang sudah tersebar cukup banyak di kota Mataram.

Berikut adalah Produk Warung Armina :

\section{Ayam Geprek}

Ayam geprek yang dijual oleh Warung Armina memiliki cita rasa yang enak, dengan potongan ayam yang dibalur tepung krispi dengan cita rasa yang gurih digeprek disajikan bersama nasi dan sambal matah atau sambal ayam geprek ditambah timun atau sayuran seperti selada. Harga 1 porsi ayam geprek yaitu Rp 10.000,-

2. Nasi Padang atau Nasi Ayam Kari

Nasi Padang seperti Nasi padang pada umumnya akan tetapi dengan citas rasa yang tidak terlalu pedas dan aging rending atau ayam kari yang empuk ditambah sambal hijau dan daun singkong yang gurih

3. Nasi Kebuli dan Nasi Goreng

Nasi kebuli adalah nasi yang dibuat dari beras basmati dimasak dengan kaldu daging kambing dan susu kambing serta minyak samin, akan tetapi Warung Armina telah melakukan Inovasi dengan tetap menggunakan beras Basmati akan tetapi mengganti daging kambing dengan daging sapi menyesuaikan dengan citarasa local yang notabene masyarakat sekitar menyukai daging kambing ditambah dengan acar dan irisan mentimun, Harga 1 Porsi nasi kebuli adalah Rp. 20.000,- dan Nasi goring adalah Rp. 10.000, Berikut adalah gambar persuasif yang dibuat oleh Tim Pengabdi yaitu : 


\section{ADMA}

Gurnal Pengabdian dan Pemberdayaan Masyarakat
2022, Vol.2, No.2, pp.293-304

Doi: $10.30812 / a d m a . v 2 i 2.1557$

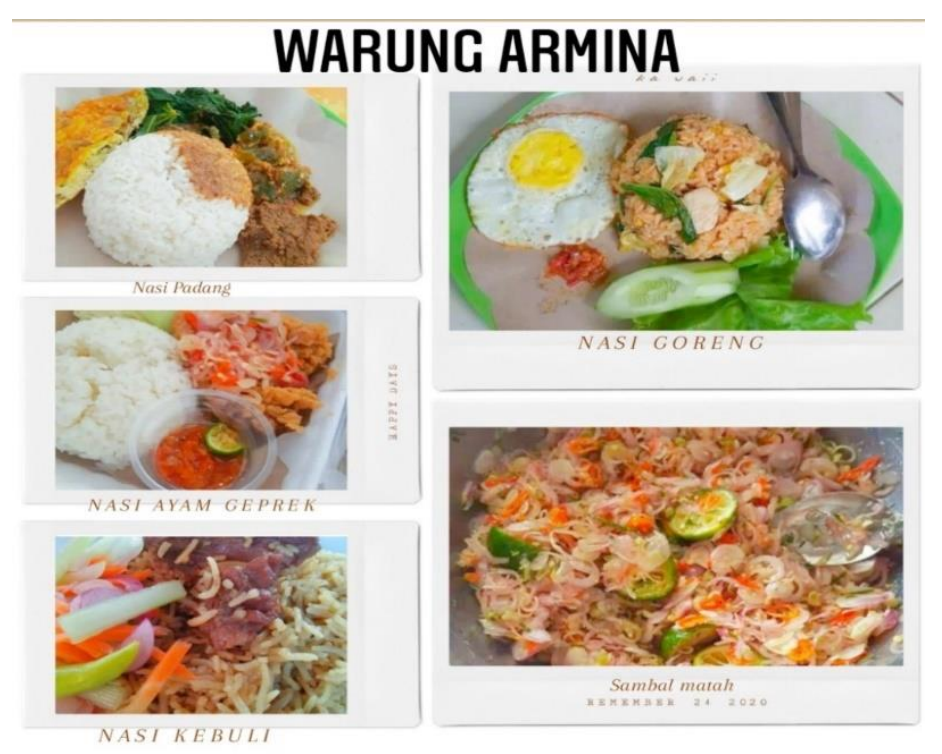

Gambar 2. Menu Warung Armina

Berikut adalah Tampilan Media Promosi yang dihasilkan dari kegiatan Pengabdian ini :

1. Menurut Murray dan Jenkins (1992) dalam (Lukitaningsih, 2013) perkembangan periklanan melalui beberapa tahap, yaitu: (1) tahap vehicle distribution, (2) tahap vehicle exposure, (3) tahap advertising exposure, (4) tahap advertising perception, (5) tahap advertising communication dan (6) tahap sales response Akan tetapi kegiatan pengabdian ini lebih berfokus pada tahap advertising communication. Menurut (Yoga Pratama \& Purwaningsih, 2021) Pambudi dalam bukunya yang berjudul "Advertising that sells" (2006), pengertian iklan adalah segala bentuk pesan yang bertujuan untuk mempromosikan barang, jasa, tempat usaha, atau ide melalui media dengan biaya tertentu sehingga pesan tersebut sampai ke sebagian besar masyarakat. Iklan dalam bahasa inggris disebut dengan "Advertisement". Iklan dapat dijumpai melalui media televisi, surat kabar, media online, blog, YouTube, billboard jalan raya, SMS, dan lain-lain. Iklan di televisi sering disebut dengan pariwara. sehingga berikut adalah gambar banner yang dihasilkan yaitu : 


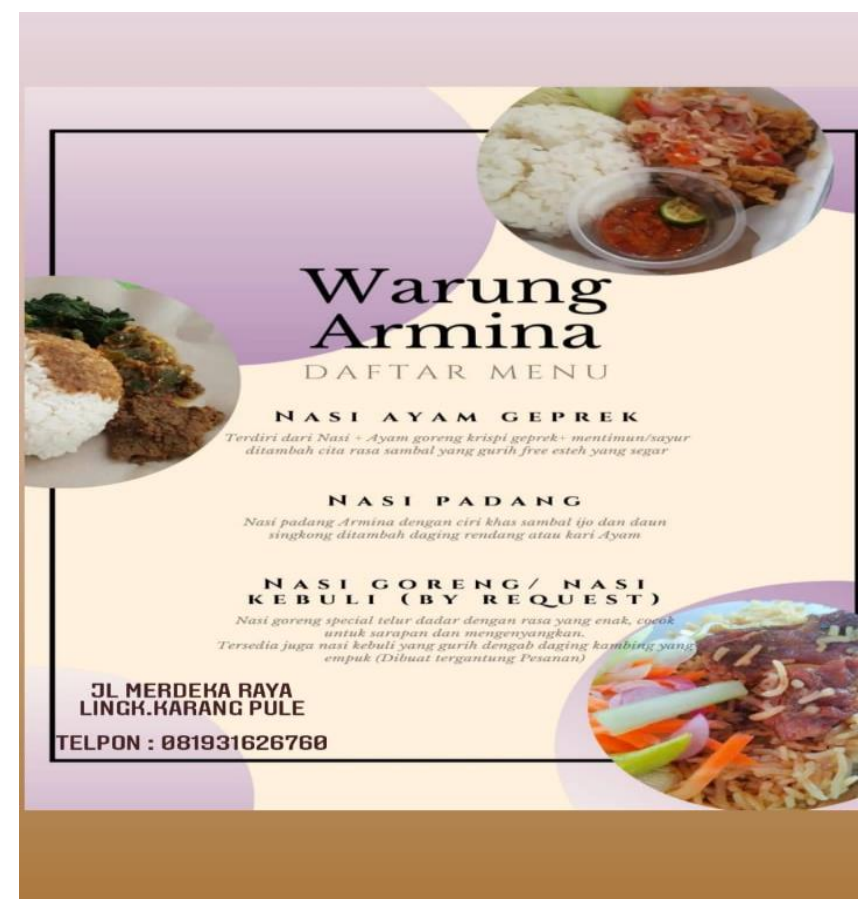

Gambar 3 Banner warung Armina

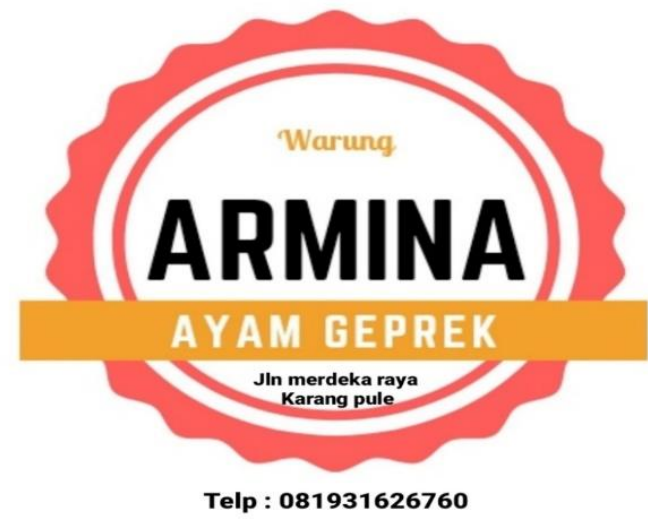

Gambar 4. Stiker kemasan warung Armina

Dalam Artikel yang ditulis oleh (Widiati, 2020) Pengemasan (packaging) secara sederhana dapat juga diartikansebagai suatu cara untuk menyampaikan barang kepada konsumen dalam keadaan terbaik dan menguntungkan. Dalam era globalisasi saat ini, kemasan mempunyai peran yang sangat penting karena akan selalu terkait dengan komoditi yang dikemas dan sekaligus merupakan nilai jual dan citra produk. Packaging is a silent salesman. Produk merupakan gabungan antara isi dan kemasan. Banyak pihak yang mengatakan bahwa kemasan hanya merupakan sampah dan menambah beban biaya penjualan. Namun tidak demikian adanya, kemasan yang standar dapat mengangkat citra suatu produk, memberikan nilai tambah dalam penjualan dan dapat melindungi produk dengan baik. Kemasan harus dapat memenuhi harapan konsumen. Kemasan bisa memberikan perlindungan produk dengan baik dari cuaca, cahaya/sinar, perubahan suhu, jatuh, tumpukan, kotoran, serangga, bakteri dan lain-lain. Struktur kemasan mudah dibuka, 
ADMA

Gurnal Pengabdian dan Pemberdayaan Masyarakat
2022, Vol.2, No.2, pp.293-304

Doi: $10.30812 /$ adma.v2i2.1557

mudah ditutup dan mudah dibawa (ergonomi). Bentuk dan ukuran menarik sesuai dengan kebutuhan menciptakan daya tarik visual bagi konsumen. Bentuk fisik kemasan ditentukan oleh sifat produk itu sendiri, sistem penjualan, mekanis, display, distribusi dan segmen pasar. Labeling harus jelas dan lengkap dan disain kemasan dirancang unik dan khas sehingga tampak berbeda dengan produk lain. Stiker tersebut dibuat untuk mempercantik kemasan packaging warung armina, Menurut Sri Julianti (2014:15) dalam artikel yang ditulis oleh (Erlyana \& Nadya, 2018), kemasan adalah wadah untuk meningkatkan nilai dan fungsi sebuah produk. Berdasarkan definisi tersebut, maka ada beberapa fungsi kemasan, yaitu: a. Melindungi kualitas produk. b. Membuat produk lebih tahan lama. c. Sebagai sarana komunikasi produk dan branding kepada konsumen. d. Membantu distribusi produk dari produsen sampai ke tangan konsumen. e. Membuat produk dapat diproduksi secara massal. f. Menjadi pemicu minat beli dengan merangsang lima panca indra konsumen, yaitu melihat, mendengar, membaui, merasa, sampai ada keputusan membeli dan menggunakan produk.

Adapun hasil yang tampilan kemasan yang dihasilkan dalam kegiatan pengabdian ini adalah sebagai berikut :

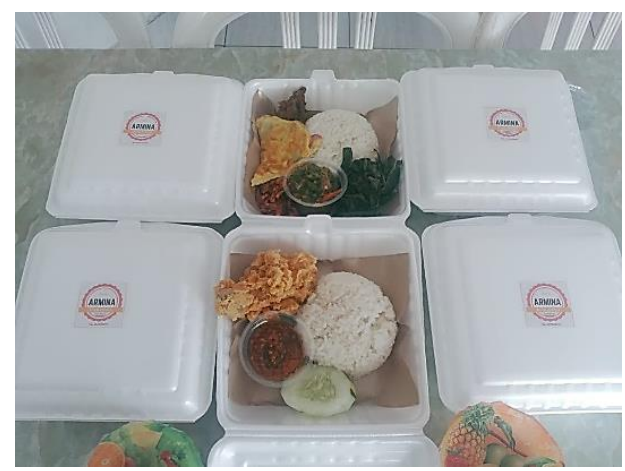

Gambar 5. Kemasan stiker

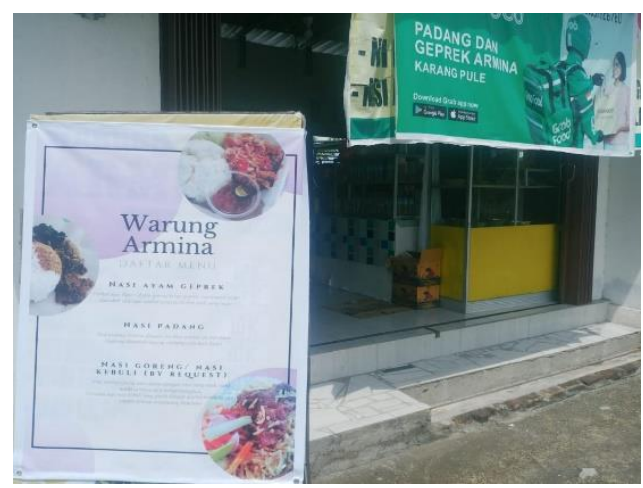

Gambar 6. Tampilan banner

Dari tampilan diatas sudah memperlihatkan bahwa Warung armina memiliki identitas yaitu stiker kemasan yang ditempel pada packaging box nasi ayam geprek juga banner sudah ditempel di depan warung yang merepresentasikan bahwa warung armina memiliki beberapa varian menu yang dijual 


\section{Kesimpulan}

Kesimpulan yang diperoleh dari kegiatan Pengabdian ini adalah Warung Armina dapat menggunakan label yang dibuat secara bersama sama berdasarkan arahan dan daya Filosofi dari Pemilik Warung Armina sendiri sehingga memudahkan kegiatan promosi kemudian tindak Lanjut Kegiatan Pengabdian yang dilaksanakan pada Warung Armina ini adalah kami selaku tim Pengabdi akan terus melihat perkembangan yang terjadi pada warung armina terutama untuk tingkat penjualan setelah dilakukannya pengabdian ini. Jika kegiatan pengabdian ini memberikan dampak yang positif maka langkah selanjutnya adalah mencoba melakukan pengabdian kepada masyarakat dalam hal manajemen organisasi UMKM sehingga seimbang antara kegiatan pemasaran dan Organisasi. Saran yang selanjutnya sebaiknya dilakukan oleh Warung Armina adalah Mengenal Pemasaran Digital/ Digital Marketing sehingga tidak terbatas pada Orang-orang sekitar saja baik melalui Facebook Ads berbayar Instagram Ads dan Whatsapp for business sehingga bisnis UMKM Warung Armina dapat berkembang dengan pesat dan dapat menjangkau Hotel-hotel maupun Instansi-instansi yang memang menerapkan Catering di Instansi mereka.

\section{Ucapan Terimakasih}

Puji Syukur Kehadirat Allah SWT yang senantiasa memberikan kesehatan dan kemampuan serta kesempatan untuk melakukan kegiatan Pengabdian ini hingga sampai pada akhirnya nanti diterbitkan dalam sebuah Jurnal dan Tidak lupa pula kami haturkan banyak-banyak terima kasih kepada :

1. Bapak Dr Anthony Anggrawan P.hd selaku Rektor Universitas Bumigora Mataram yang selalu mendukung kegiatan Universitas Bumigora Mataram

2. LPPM Universitas Bumigora Mataram yang dengan semangat terus memberikan saran saran untuk perbaikan kegiatan Pengabdian maupun Penelitian.

3. Bapak Haji Mawardi dan Ibu Hj Harmiati Selaku Pemilik Warung Armina yang sudah sangat kooperatif dalam membantu penulis memperoleh data dan berkenan memberikan informasi-informasi penting untuk kegiatan Pengabdian kepada Masyarakat ini.

4. Tim Desain dari Percetakan Inti media Grafika yang begitu Professional dan Tanggap dalam merespon serta menjadi Pendengar yang baik untuk mitra.

5. Dan untuk semua Tim yang terlibat dalam kegiatan Pengabdian ini yang tidak bisa kami sebutkan secara rinci. 


\section{DAFTAR PUSTAKA}

Ainurrofiqin, M. (2021). 99 Strategi Branding di Era 4.0: Kupas Tuntas Metode Jitu Membangun Citra Baik, Meyakinkan Pelanggan, dan Membangun Kesadaran Merek. Retrieved from https://books.google.co.id/books?id=ik5LEAAAQBAJ\&pg=PA280\&lpg=PA280\&dq=jingle+iklan+i ndofood\&source $=$ bl\&ots $=k 9$ alAJTVBQ\&sig $=$ ACfU3U0NmwuSavf7aDfkaKAxJ6MQQUK81 w\&hl=i $\mathrm{d} \& s a=X \& v e d=2 a h U K E$ wiYoMPWIsD0AhUsSmwGHelrB6kQ6AF6BAgnEAM\#v=onepage\&q=jingl e iklan indofood $\& f=f a$

Erlyana, Y., \& Nadya, N. (2018). Analisis Desain Kemasan Mi Instan Edisi Khusus Indomie Tempo Doloe. Titik Imaji, 1(1), 17-29. https://doi.org/10.30813/.v1i1.1087

Hayati, S. R., Amelia, S., \& Putri, M. (2020). Inovasi Produk Dan Kemasan Pada Kecamatan Gamping Kabupaten Sleman. Jurnal Pengabdian Masyarakat, 1(2), 87-100. Retrieved from http://ejournal.iainsurakarta.ac.id/index.php/transformatif/article/view/2985

Hintermann Geneva, B. (n.d.). World Intellectual Property Organization Pengantar Merek untuk Usaha Kecil dan Menengah Intellectual Property for Business Series Membuat Sebuah Merek 1 Number. Retrieved from www.wipo.int/sme/

Kotler, P. (2014). Kotler on marketing : how to create, win, and dominate markets.

Lukitaningsih, A. (2013). Iklan Yang Efektif Sebagai Strategi Komunikasi Pemasaran. Jurnal Ekonomi Dan Kewirausahaan, 13(2), 116-129.

Pratama, D., Supatminingsih, T., Dinar, M., Jl Raya Pendidikan, M., \& UNM Gunung Sari Baru Makassar, K. (n.d.). Analisis Bauran Pemasaran Usaha Kue Tradisional Dange Di Kecamatan Mandalle Kabupaten Pangkep.

Puspitasari, F., \& Gusfa, H. (n.d.). Strategi Promosi Online Shop Melalui Sosial Media Dalam Membangun Brand Engagement (Studi Kasus: Promosi Brand Sally Heart Melalui Akun Instagram @ukhtisally).

Widiati, A. (2020). Peranan Kemasan (Packaging) Dalam Meningkatkan Pemasaran Produk Usaha Mikro Kecil Menengah (Umkm) Di "Mas Pack" Terminal Kemasan Pontianak. JAAKFE UNTAN (Jurnal Audit Dan Akuntansi Fakultas Ekonomi Universitas Tanjungpura), 8(2), 67-76. https://doi.org/10.26418/jaakfe.v8i2.40670

Yoga Pratama, A. D., \& Purwaningsih, N. K. (2021). Analisis Struktur Iklan Warung Bu Kris. KULTURISTIK: Jurnal Bahasa Dan Budaya, 5(1), 51-59. https://doi.org/10.22225/kulturistik.5.1.2739

Yuliani, R., \& Widyakanti, W. (2020). Peningkatan Penjualan Melalui Inovasi Kemasan dan Label Pada UMKM. Jurnal Keuangan Umum Dan Akuntansi Terapan, 2(2), 71-76. Retrieved from http://jurnal.pknstan.ac.id/index.php/KUAT/article/view/990 


\section{ADMA}

Gurnal Pengabdian dan Pemberdayaan Masyarakat
2022, Vol.2, No.2, pp.293-304

Doi: $10.30812 / a d m a . v 2 i 2.1557$ 